Western University

Scholarship@Western

Department of Economics Research Reports

Economics Working Papers Archive

1984

\title{
Tariff Policy and Equilibrium Growth in the World Economy
}

Miguel A. Kiguel

Ian Wooton

Follow this and additional works at: https://ir.lib.uwo.ca/economicsresrpt

Part of the Economics Commons

Citation of this paper:

Kiguel, Miguel A., Ian Wooton. "Tariff Policy and Equilibrium Growth in the World Economy." Department of Economics Research Reports, 8408. London, ON: Department of Economics, University of Western Ontario (1984). 
RESEARCH REPORT 8408

TARIFF POLICY AND EQUILIBRIUM GROWTH

IN THE WORLD ECONOMY

Miguel A. Kiguel

University of Maryland at College Park

and

Ian Wooton

The potential for each region's use of commercial policy in a dynamic asymmetric North-South model is examined. The North is the producer of a good which may be consumed or invested, manufactured in a solowtype economy. The South produces consumer goods in a Lewis labour-surplus economy. It is shown that, although a country with monopoly power in trade may improve its welfare in the short run through imposing a tariff, such a policy might ultimately be detrimental.

Ian Wooton Department of Economics University of Western Ontario Apri1, 1984 London, Ontario N6A 5C2 Canada

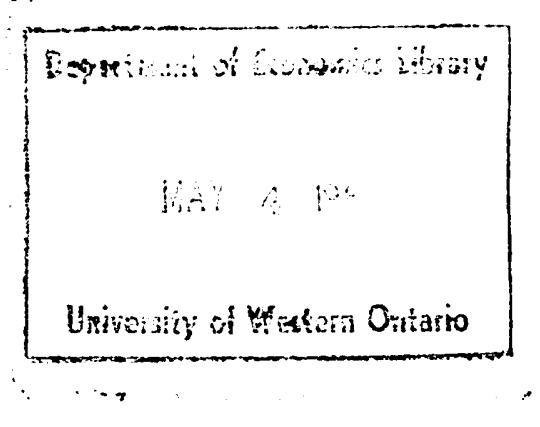




\section{Introduction}

The impact of tariff policy on welfare, the terms of trade, and the patterns of production, consumption, and trade has been the subject of extensive research. Johnson (1965) and Bhagwati (1971), among others, studied the issue in a model of the world economy that abstracted from economic growth and considered countries that, except for their relative factor endowments, were completely identical.

The effect of tariff policy can change quite dramatically once growth is taken into account. It is well known that a tariff will, in general, affect the structure of production and consumption and, when the countries under study are large, it will affect their offer curves over time and the paths of their optimal tariff. Hence it is certainly not clear whether the optimal tariff analysis derived from a static framework will be consistent with one that takes into account economic growth. In particular, a tariff that is designed to maximize long-run welfare will likely differ from the one which takes fullest advantage of a country's short-run monopoly power in trade.

Another important issue is that there may be structural differences between the countries under study which go beyond the disparity in factor endowments. The world might be regarded as being divided into two dissimilar regions, developed and less-developed countries. An extreme way of depicting the differences between these two groups of countries is to assume that the former are industrialized and have highly integrated factor markets, while the latter produce and trade primary products but also have large subsistence sectors. 
A proposal for integrating these dissimilar regions, commonly called "North" and "South", in terms of a dynamic model of the world economy was first suggested by Findlay (1980). He divides the world into two regions, the main asymmetry being the structure of their labour markets. Although this assumption alone does not exhaust the existing differences between the developed and less-developed nations, it certainly captures a fundamental one. ${ }^{1}$

This paper will attempt to study optimal tariff policies in a dynamic model of the world economy. Findlay's model will provide a useful framework for the analysis. The optimal tariff policy for each country in the long-run steady-state equilibrium will be derived, the emphasis of the paper being on how this contrasts with that of the "myopic" policymaker.

The essay is organized as follows. Section 2 presents the basic structure of Findlay's model. Section 3 discusses the short-run and longrun effects of the imposition of a tariff by either region and derives the optimal conditions associated with it. Finally, the main results and conclusions are presented in Section 4.

\section{The Analytical Framework}

Following Findlay, the world economy consists of two regions, the North and the South. Each region is specialized in the production of a single good, using the services of capital and labor in a neoclassical production function with constant returns to scale. The North produces manufactures which can be used for either consumption or investment. Capital consists of a stock of manufactures. The labor force grows over time at a constant rate and its size is given at any instant. Markets are perfectly competitive and there is always full employment of the factors of production. A constant fraction of output is saved and invested domestically. 
The South produces primary products which are used exclusively for consumption. Capital, as in the North, consists of a stock of manufactures. Labor is in perfectly elastic supply from the "hinterland" at a fixed real wage in terms of the primary product. ${ }^{2}$ There is perfect competition, so labor is hired up to the point at which its marginal productivity is equal to the fixed real wage. The capital-1abor ratio is uniquely determined, hence total employment depends on the size of the capital stock. Saving is exclusively out of profits, wages being entirely consumed.

The regions' characteristics imply that the North's economy corresponds to that of the Solow neoclassical growth model whereas the economy of the South is that of the Lewis model of economic development with unlimited supplies of labor. ${ }^{3}$ As a prelude to the analysis of tariff policy, the basic structure of Findlay's model is presented. The production function for manufactures in the North is

$$
Y_{N}=q\left(k_{M}\right) L_{N}
$$

where $Y_{N}$ is total income, $I_{N}$ the employment, and $k_{M}$ the capital-labor ratio in manufacturing. $I_{\mathrm{N}}$ grows over time at a constant rate $n$,

$$
\tilde{I}_{N}=\widetilde{I}_{N} \exp (n t),
$$

and $\mathrm{k}_{\mathrm{M}}$ at any instant is determined by past saving. A constant proportion 8 of output is saved and the remainder of income is consumed. The import demand function of the North is

$$
I_{N}=m\left[\theta,(1-s) q\left(k_{M}\right)\right] L_{N}
$$

where $\theta$ are the terms of trade (manufactures per unit of primary products) and it is assumed that $m_{1}<0<m_{2}$. 
The per capita production function for primary products in the South is

$$
\pi=\pi\left(k_{P}\right)
$$

where $k_{P}$ is the capital-labour ratio in primary production. For profit maximization

$$
\pi\left(k_{P}\right)-\pi^{\prime}\left(k_{P}\right) k_{P}=\tilde{w}
$$

where $\tilde{w}$ is the fixed real wage in terms of primary products. There is a unique capital-labor ratio, $\mathrm{k}_{\mathrm{P}}^{*}$, that satisfies (5). [Asterisks represent long-run equilibrium values of corresponding unstarred variables.] Output is a flow of primary products and capital is a stock of manufactures, hence the rate of profit in the south is

$$
\gamma=\theta \pi^{\prime}\left(k_{\mathrm{p}}^{*}\right)
$$

while the common growth rate of total capital, output, and employment in the South is

$$
g=\sigma \gamma
$$

where $\sigma$ is the rate of saving out of profits. The import demand function for the South is

$$
I_{S}=\left\{\theta \sigma \pi^{\prime}\left(k_{\mathrm{P}}^{*}\right) k_{\mathrm{P}}^{*}+\mu\left[\theta^{-1}, \tilde{\mathrm{w}}+(1-\sigma) \pi^{\prime}\left(\mathrm{k}_{\mathrm{P}}^{*}\right) k_{\mathrm{P}}^{*}\right] \mathrm{I}_{S}\right.
$$

$I_{S}$ being total employment in the South, determined by

$$
\mathrm{L}_{\mathrm{S}}=\mathrm{K}_{\mathrm{S}} / \mathrm{k}_{\mathrm{P}}^{*},
$$

and $\mu[]$ being the consumption demand for manufactures, where $\mu_{1}<0<\mu_{2}$. The imports of the South consist of manufactures for both consumption and investment.

In the absence of international capital movements, trade must balance at every instant such that 


$$
\theta I_{N}=I_{S}
$$

Substituting (3) and (8) and letting $\lambda=I_{S} / I_{N}$, the ratio of employment in the two regions, $(10)$ can be solved to obtain an implicit function for the instantaneous terms of trade,

$$
\theta=\frac{\lambda \mu\left[\theta^{-1}, \tilde{w}+(1-\sigma) \pi^{\prime}\left(k_{\tilde{p}}^{*}\right) k_{\mathrm{P}}^{*}\right)}{m\left[\theta,(1-s) q\left(k_{M}\right)\right]-\lambda \sigma \pi^{\prime}\left(\mathrm{k}_{\mathrm{P}}^{*}\right) \mathrm{k}_{\mathrm{P}}^{*}}
$$

In the long run, the rates of growth of the two regions must be the same. The natural growth rate of the North is constant, and so it follows from (6) and (7) that there is a unique value

$$
\theta *=\frac{\mathrm{n}}{\sigma \pi^{\prime}(\mathrm{k} *)}
$$

The steady-state value of the North's capital-labor ratio is given by the condition

$$
k_{M}^{*}=\frac{s q\left(k_{M}^{*}\right)}{n}
$$

If both $\theta$ and $k_{M}$ are at their steady-state values then (11) implicitly determines the corresponding long-run ${ }^{4}$ steady-state value of $\lambda$ as

$$
\lambda *=\frac{\theta \operatorname{m}\left[\theta *,(1-\mathrm{s}) \mathrm{q}\left(\mathrm{k}_{\mathrm{M}}^{*}\right)\right]}{\mu\left[\frac{1}{\theta^{*}}, \tilde{\mathrm{w}}+(1-\sigma) \pi^{\prime}\left(\mathrm{k}_{\mathrm{P}}^{*}\right) \mathrm{k}_{\mathrm{P}}^{*}\right]+n \mathrm{k}_{\mathrm{P}}^{*}}
$$

In the sections. which follow, the potential gains to regions from their use of commercial policy are considered. In particular, the welfare implications of a tariff, that is a tax on the importation of the foreign good, is discussed. 


\section{Tariff Policy}

3.1 A tariff imposed by the North

Suppose the North attempts to exploit its monopoly power in trade in order to improve its long-run welfare. From (12), given $n$, the North cannot affect the steady-state terms of trade. Its optimal long-run policy is then that of a small open economy, free trade.

The North has monopoly power in the short run. Since trade at all times must be balanced and capital stocks are given by history, there must be a temporary adjustment in the terms of trade in response to a tariff. Consequently the North is able to achieve some short-run gains. These gains cannot be maintained, as growth rates are not equal, and the policy in the long run results in welfare losses for both regions.

This is illustrated in the offer curve diagram of Figure $1.0_{\mathrm{N}}^{0}$ is the per capita offer curve of the North when there is no tariff. It intersects with $\lambda * 0_{S}^{0}$, where $0_{S}^{0}$ is the per capita offer curve of the South, at the long-run terms of trade $\theta *$. Should the North impose a tariff of $t \%$ its offer curve would be $0_{N}^{t}$. In the short run $\lambda *$ cannot change and balanced trade would be at terms of trade $\hat{\theta}$ with the North on a higher indifference curve than previously. At $\hat{\theta}$, the rate of growth of the capital stock of the South is less than $n$ and consequently its employment does not expand as rapidly as that of the North. $\lambda$ declines and causes $\lambda 0_{\mathrm{S}}^{0}$ to shrink until it intersects $0_{N}^{t}$ at $\theta *$. The welfare of the North is lower and that of the South has also been reduced.

If the time horizon of the policymaker in the North were short, he would impose an ultimately detrimental tariff in order to achieve the shortrun gains. If his rate of discount were lower, he would value future consumption more highly and he would set a lower, or zero, tariff. 


\subsection{A tariff imposed by the South without redistribution}

Suppose that the South wishes to increase its long-run welfare through tariff policy. The real wage, in terms of the primary product, cannot be changed and so the capital-labor ratio is immutable. Hence the rental on capital $\pi^{\prime}\left(k_{p}^{*}\right)$ is fixed, but the rate of profit depends on the domestic terms of trade. The domestic terms of trade, when the South imposes a tariff, are $\frac{\theta}{1+t}$, where $\theta$ is the instantaneous world terms of trade. The rate of profit in the South is

$$
\gamma=\frac{\theta}{1+t} \pi^{\prime}\left(\mathrm{k}_{\mathrm{P}}^{*}\right)
$$

In the steady state, growth rates of the North and the South must be equal

$$
\mathrm{n}=\mathrm{g}=\sigma \gamma \text {. }
$$

In consequence, given $n$, the world terms of trade are

$$
\theta=\frac{n(1+t)}{\sigma \pi^{\prime}\left(k_{\mathrm{P}}^{*}\right)}=\theta *(1+t)
$$

where $\theta *$ is the original steady-state terms of trade, in the absence of any trade distortion. The domestic terms of trade of the South are $\theta *$, that is they are independent of any tariff. Thus the impact of the South's tariff policy falls entirely on the international terms of trade.

It can be shown that the South may affect the steady-state employment ratio, $\lambda *(t)$, and thereby improve its welfare. A suitable measure of the welfare of the South might be either the income or the level of employment in the modern sector relative to the level of Northern employment. With an unredistributed tariff these goals coincide and hence any policy which maximizes employment is undoubtedly optimal. The imports of the North are 


$$
I_{N}=m\left[\theta,(1-s) q\left(k_{M}\right)\right] L_{N}
$$

The imports of the South will now depend upon the domestic terms of trade. [The consequences of the redistribution of the tariff revenue will be discussed in sub-section 3.3.$]$

$$
I_{S}=\left\{\frac{\theta}{1+t} \sigma \pi^{\prime}\left(k_{P}^{*}\right) k_{P}^{*}+\left[\frac{1+t}{\theta}, \tilde{w}+(1-\sigma) \pi^{\prime}\left(k_{P}^{*}\right) k_{P}^{*}\right]\right\} L_{S}
$$

In the long run the terms of trade will be at their steady-state value and the capital-labor ratio of the North will be k. Substituting (3), (17), and (18) into the trade balance equation, and rearranging, the steady-state employment ratio is

$$
\lambda *(t)=\frac{\theta *(1+t) \mathrm{m}\left[\theta *(1+t),(1-s) \mathrm{q}\left(\mathrm{k}_{\mathrm{M}}^{*}\right)\right]}{\mu\left[\frac{1}{\theta_{*}^{*}}, \tilde{\mathrm{w}}+(1-\sigma) \pi^{\prime}\left(\mathrm{k}_{\mathrm{P}}^{*}\right) \mathrm{k}_{\mathrm{P}}^{*}\right]+\mathrm{nk}_{\mathrm{P}}^{*}}
$$

which differs from (14). Hence the South may use tariff policy to increase its welfare. The optimal tariff is that which maximizes $\lambda *(t)$, because $I_{N}$ is determined at all times according to (2).

$$
\frac{d \lambda *(t)}{d t}=\frac{\lambda *(t)}{1+t}\left\{1-\eta_{N}\right\}
$$

where $\eta_{N}$ is the elasticity of per capita import demand in the North with respect to $\theta$. The welfare of the South is maximized when the tariff is set such that the import elasticity of demand of the North is unity.

This result may be understood by closely examining equation (19). The per capita imports of the South are independent of the tariff and so the denominator is constant with respect to the tariff. Hence maximizing $\lambda *(t)$ is equivalent to maximizing the revenue from trade. The South is, in a sense, a price-setting monopolist whose revenues are maximized at the point of unit elasticity on the demand curve for its products. 
What is the short-run impact of the South's policy? In the short run capital stocks are fixed and the terms of trade must adjust to achieve trade balance.

$$
\theta=\frac{\lambda \mu\left[\frac{1+t}{\theta}, w+(1-\sigma) \pi^{\prime}\left(k_{P}^{*}\right) k_{P}^{*}\right.}{m\left[\theta,(1-s) q\left(k_{M}\right)\right]-\frac{\lambda}{1+t} \sigma \pi^{\prime}\left(k_{P}^{*}\right) k_{P}^{*}}
$$

Differentiating (21) with respect to $t$, and rearranging

$$
\frac{d \theta}{d t}=\frac{\theta}{1+t}-\frac{\theta}{1+t} \frac{\lambda_{\mu}}{\theta_{m}} \frac{\left(1-\eta_{N}\right)}{\left(1-\eta_{S}-\frac{\theta_{m}}{\lambda_{\mu}} \eta_{N}\right)}
$$

when $\eta_{S}$ is the price elasticity of import demand of the South. The MarshallLerner condition is assumed to hold, and hence

$$
\eta_{S}+\frac{\theta_{m}}{\lambda_{\mu}} \eta_{N}>1
$$

Thus: if $\eta_{\mathrm{N}}=1, \frac{\mathrm{d} \theta}{\mathrm{dt}}=\frac{\theta}{1+\mathrm{t}}$;

$$
\text { if } \eta_{\mathrm{N}}<1, \frac{\mathrm{d} \theta}{\mathrm{dt}}>\frac{\theta}{1+\mathrm{t}}
$$

and if $\eta_{\mathrm{N}}>1, \frac{\mathrm{d} \theta}{\mathrm{dt}}<\frac{\theta}{1+t}$.

Differentiating (17) with respect to $t$, the change in the long-run terms of trade due to a tariff may be found

$$
\frac{d \theta}{d t}=\theta *=\frac{\theta}{1+t} \text {. }
$$

Hence if the initial steady-state equilibrium is in the inelastic region of the North's offer curve $\left(\eta_{\mathrm{N}}<1\right)$ the terms of trade will initially overshoot their long-run value. 5 The improvement in the terms of trade will result in a higher rate of profit in the South and hence a rate of capital accumulation 
exceeding that in the North. The rate of growth in employment will increase accordingly and $\lambda$ will rise until growth rates are equalized at the new steady-state terms of trade.

The analysis of this section is illustrated in Figure 2. $\lambda *(i)$ is the long-run employment ratio as a result of the tariff $i$ set by the South. The initial steady-state trade equilibrium occurs on the inelastic portion of the North's offer curve at point a. The South chooses the tariff $t$ such that the new steady-state equilibrium will be at the unit elastic point $c$ of the North's offer curve, in order to maximize long-run employment. In the short run, so that trade might be balanced, $\theta$ will increase beyond its long-run value and trade will occur at b.

\subsection{Redistribution and the optimal tariff for the South}

The preceding analysis did not take into account the revenue produced by the tariff. If this is redistributed, the optimal tariff will differ from that of sub-section 3.2.

It is assumed that tariff revenues are given to workers for additional consumption. 6 The per capita tariff income, in terms of the primary product, is

$$
T=\frac{t I_{S}}{\theta I_{S}} .
$$

The imports of the South become

$$
I_{S}=\left\{\frac{\theta}{1+t} \sigma \pi^{\prime}\left(k_{\mathrm{P}}^{*}\right) k_{\mathrm{P}}^{*}+\mu\left[\frac{1+t}{\theta}, \tilde{\mathrm{w}}+(1-\sigma) \pi^{\prime}\left(k_{\mathrm{P}}^{*}\right) k_{\mathrm{P}}^{*}+T\right]\right\} L_{S}
$$

where the income available for consumption has been increased by the proceeds of the tariff. 
In the long run the terms of trade will be at their steady-state value and the capital-labor ratio of the North will be $\mathrm{k}_{\mathrm{M}}^{*}$. Substituting (3), (17), and (26) into the trade balance equation, and rearranging, the steady-state employment ratio is

$$
\lambda *(t)=\frac{\theta *(1+t) m\left[\theta *(1+t),(1-s) q\left(k_{M}^{*}\right)\right]}{\mu\left[\frac{1}{\theta *}, \tilde{w}+(1-\sigma) \pi^{\prime}\left(k_{P}^{*}\right) k_{P}^{*}+\frac{t}{\theta *(1+t)}\left\{\mu[]+n k_{P}^{*}\right\}\right]+n k_{P}^{*}}
$$

The welfare criteria of the South, employment and income, are no Ionger entirely compatible. The redistribution of the tariff revenue implies, for a given volume of trade, fewer Southern workers will be employed, each with a larger total income. Total income is again maximized at the point of unit elasticity on the North's offer curve, but employment will be less than when the revenues were unredistributed.

Suppose that, instead of income maximization, the South chooses to maximize its steady-state employment by the imposition of a tariff. Differentiating (27) with respect to $t$ yields

$$
\frac{d \lambda *(t)}{d t}=\frac{\theta * m[]}{\mu[]+n k_{\mathrm{P}}^{*}}\left(1-\eta_{\mathrm{N}}-B\right)
$$

where

$$
B=\frac{\frac{\mu_{2}}{\theta *(1+t)}}{1-\frac{t \mu_{2}}{\theta *(1+t)}}
$$

Now $\frac{t \mu_{2}}{\theta *(1+t)}$ is the demand for manufactures generated from the redistribution of the tariff on the importation of one unit of manufactures and is hence assumed to be positive yet less than unity, so $B>0$. The optimal tariff is 
therefore smaller than that which maximizes relative income. The optimization exercise is no longer that of a simple monopolist who chooses that point on the demand curve for his good at which revenue is maximized. The redistribution of the tariff revenue affects his own demand for imports. The higher the tariff, the greater the demand of the individual worker in the South for mamfactures. If his import demand rises more proportionately to the increase in revenues, then employment will be depressed.

The solution is illustrated in Figure $3, \hat{0}_{s}^{t}$ represents the offer curve of the South when the revenue of a tariff $t$ is redistributed for consumption. The relative income-maximizing long-run equilibrium for the South will result in trade at point $c$, at the unit elastic point on the offer curve of the North, while the relative employment-maximizing long-run equilibrium for the South will result in trade at $b$ on the inelastic portion of the North's offer curve. It is clear that, if the policymaker wishes to achieve some mixture of his objectives, trade would be at some point between $b$ and $c$ on the offer curve of the North.

\section{Summary and Conclusions}

The objective of this paper was to determine the consequences of tariff policy in a world comprising two structurally different regions, each specialized in the production of a single good. The North is a Solow-type economy which produces the investment good, while the South is a Lewis-type labor-surplus economy producing only consumption goods.

Within this framework it has been shown that the short-run and the long-run effects of imposing a tariff are very different. The familiar result that countries with monopoly power in trade can improve their welfare using tariffs may hold only in the short run. The asymmetry of the world economy results in a dissimilarity between the long-run impact of each region's policies. 
The North, due to its inability to affect the long-run terms of trade, cannot improve its long-run welfare. In fact, any tariff it might adopt to achieve immediate gains would be deleterious in the steady state. Therefore whether or not the North chooses to impose a tariff will depend on its rate of time preference. On the contrary, the short-run benefits to the South of a tariff extend into the long run. The optimizing policymaker will undoubtedly impose a non-zero tariff.

It can be shown that these results are not affected in essence if capital is allowed to move freely between regions.

The results derived here, that the North is impotent and the South a perfect monopolist in the long run, are in sharp contrast to those of Kemp and Ohyama (1978). In that paper the inability of the southern region to produce consumption goods enables the North to fully exploit, through tariffs, its monopoly power in trade. 
FOOTNOTES

\begin{abstract}
*
The authors wish to thank Professor Ronald Findlay, an anonymous referee, and members of seminars at Columbia University and the University of Western Ontario for their comments on drafts of this paper.

${ }^{1}$ Another approach is that of Taylor (1981) who models the North using
\end{abstract} the Keynesian assumption of excess capacity whereas the Findlay model considers a neo-classical, full-employment North. As a result, one might expect commercial policy in the two models to have different consequences. ${ }^{2}$ It could equally be assumed that the real wage is fixed in terms of a basket of consumption goods, without any substantial effect on the results.

${ }^{3}$ Although the modern sector faces an infinitely elastic supply of labor, it is not necessary to assume that the marginal product of labor in the subsistence sector is zero.

${ }^{4}$ It may be that, as the modern sector grows, the supply of labor at the fixed wage may "dry up" and the wage will have to rise in order to induce the inflow of more workers. Thus the discussion here is of a "quasi-Iong-run" steady state, in which the Southern labor remains in elastic supply.

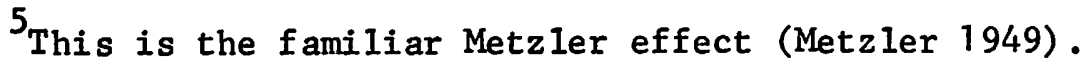

${ }^{6}$ Were the tariff revenue given for capital accumulation, the domestic terms of trade would change. The analysis would be considerably more complicated, but a non-zero tariff for the South would still be determined. It is also assumed that the tariff redistribution is not used to subsidize the wage. Otherwise the capital-labor ratio would fall until the marginal product of labor equaled the wage cost to the firm. The rate of profit would be higher initially, with a consequent deterioration in the Southern steady-state terms of trade. 


\section{REFERENCES}

Bhagwati, J. N. (1971) "The Generalized Theory of Distortions and Welfare" in J. N. Bhagwati, R. W. Jones, R. A. Mundell and J. Vanek (eds.), Trade, Balance of Payments, and Growth: Papers in International Economics in Honor of Charles $P_{0}$ Kindleberger (Amsterdam: North-Holland).

Burgstaller, A. and N. Saaverda-Rivano (1981) "Capital Mobility and Growth in a North-South Mode1," Columbia University Department of Economics Discussion Paper 111.

Findlay, R. (1980) "The Terms of Trade and Equilibrium Growth in the World Economy," American Economic Review 70, 291 -299.

Johnson, H. G. (1965) "Optimal Trade Intervention in the Presence of Domestic Distortions" in R. Caves, H. G. Johnson and P. B. Kenen (eds.), Trade, Growth, and the Balance of Payments (New York: Rand McNally).

Kemp, M. C. and M. Ohyama (1978) "On the Sharing of Trade Gains by Resource-poor and Resource-rich Countries," Journal of International Economics 8, 93-115.

Metzler, I. (1949) "Tariffs, the Terms of Trade, and the Distribution of National Income," Journal of Political Economy 57.

Taylor, L. (1981) "South-North Trade and Southern Growth: Bleak Prospects from the Structuralist Point of View," Journal of International Economics $11,589-602$. 


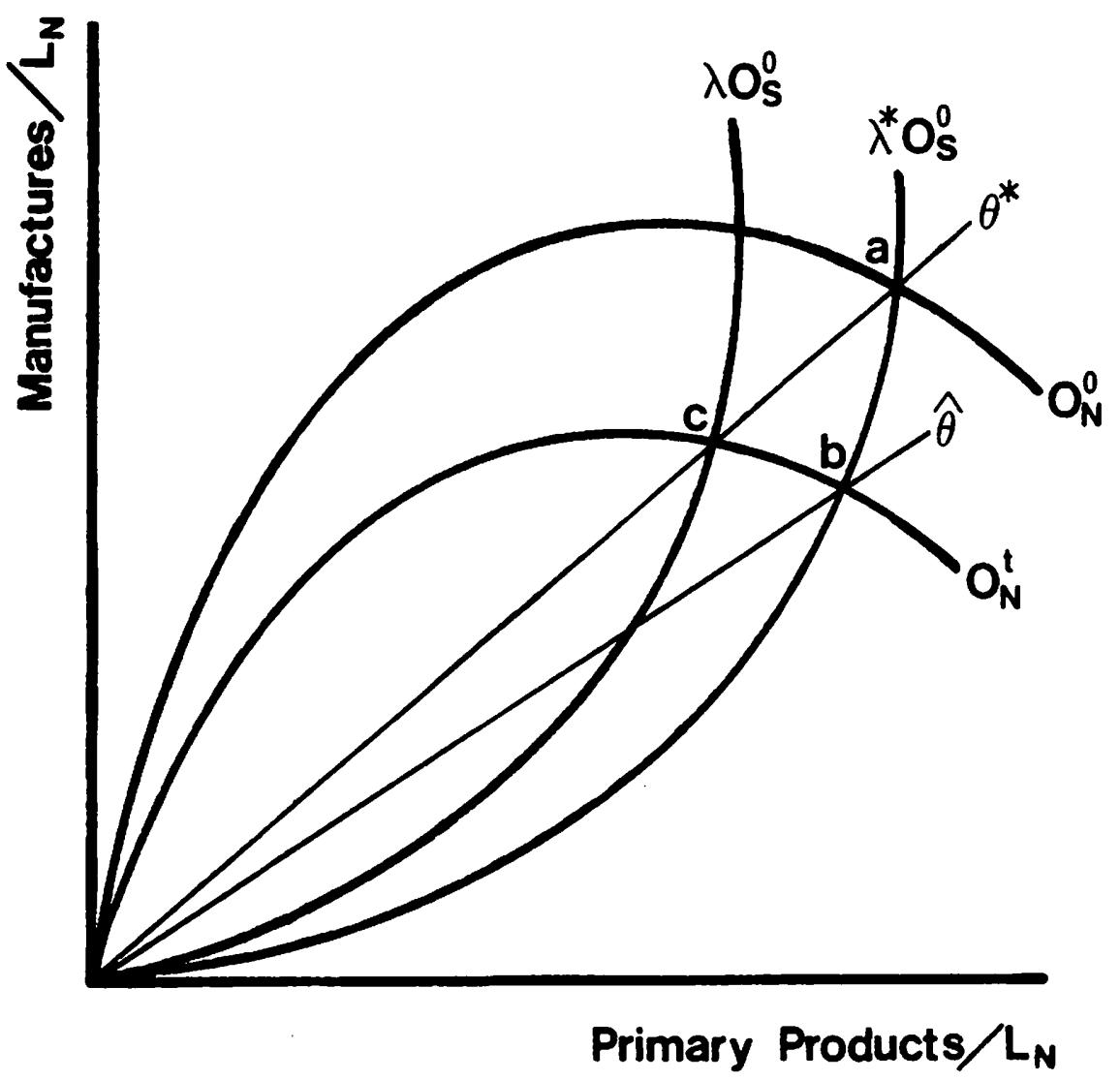

FIGURE 1 


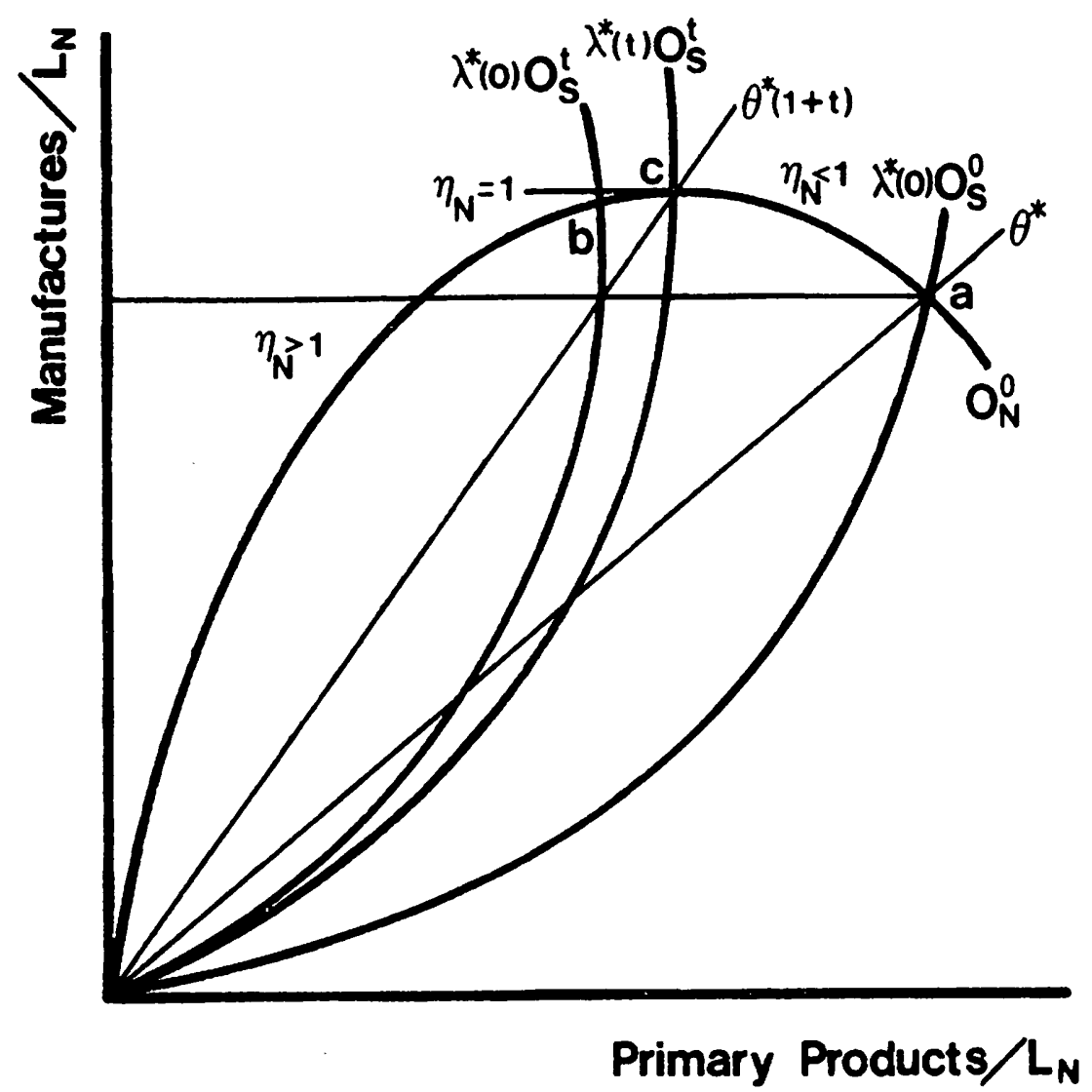

FIGURE 2 


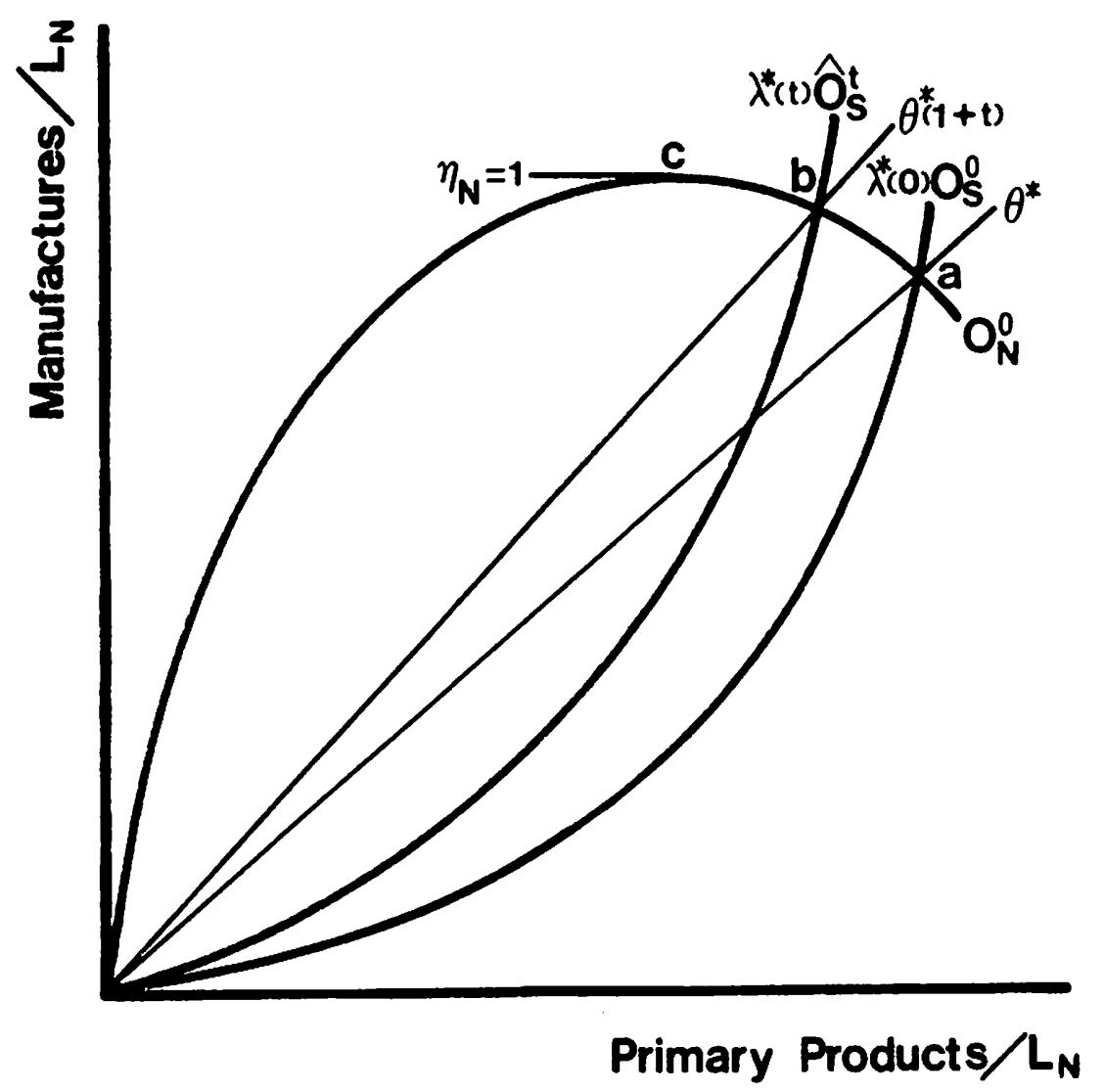

FIGURE 3 